\title{
A numerical model to study the role of surface textures at TDC reversal in the piston ring to cylinder liner contact
}

\author{
N. Morris ${ }^{1}$, R. Rahmani ${ }^{*}$, H. Rahnejat ${ }^{1}$, P.D. King ${ }^{1}$ and S. Howell-Smith ${ }^{2}$ \\ ${ }^{1}$ Wolfson School of Mechanical and Manufacturing Engineering, Loughborough \\ University, Leicestershire, UK \\ ${ }^{2}$ Capricorn Automotive Ltd, Basingstoke, UK \\ *Corresponding author: R.Rahmani@lboro.ac.uk
}

\begin{abstract}
Minimisation of parasitic losses in the internal combustion engine is essential for improved fuel efficiency and reduced emissions. Surface texturing has emerged as a method palliating these losses in instances where thin lubricant films lead to mixed or boundary regimes of lubrication. Such thin films are prevalent in contact of compression ring to cylinder liner at piston motion reversals because of momentary cessation of entraining motion. The paper provides combined solution of Reynolds equation, boundary interactions and a gas flow model to predict the tribological conditions, particularly at piston reversals. This model is then validated against measurements using a floating liner for determination of in-situ friction of an engine under motored condition. Very good agreement is obtained. The validated model is then used to ascertain the effect of surface texturing of the liner surface during reversals. Therefore, the paper is a combined study of numerical predictions and the effect of surface texturing. The predictions show that some marginal gains in engine performance can be expected with laser textured chevron features of shallow depth under certain operating conditions.
\end{abstract}

Keywords: Internal combustion engine; surface texture; piston ring; friction; lubrication

\section{Nomenclature}

A

Apparent contact area

$m^{2}$

$A_{a}$

Asperity contact area

$m^{2}$

$A_{v}$

Lubricated contact area

$m^{2}$

$A_{i}$

Cross sectional area of control volume $i$

$m^{2}$

$b$

Ring axial face-width

$m$

$d$

Ring width in the radial direction (ring thickness)

$m$ 
$E^{\prime} \quad$ Composite Young's modulus of elasticity

Total friction

Boundary friction

$N$

$f_{v}$

Viscous friction $N$

F

Total load on the ring $N$

$F_{5 / 2}, F_{2} \quad$ Statistical functions

$F_{e}$

Ring elastic (tension) force $N$

$F_{g}$

Gas force acting behind the ring $N$

$h$

Film shape

$m$

$h_{d}$

Maximum texture depth

$m$

$h_{m}$

Minimum film thickness

$m$

$h_{t}$

Texture profile

$m$

$h_{s}$

Profile of the compression ring

$m$

$h_{1}$

Piston top land to liner gap

$m$

Ring cross-sectional second moment of area

$m^{4}$

Ring peripheral length

$m$

$l_{c}$

Thickness of chevron leg

$m$

$l_{1}$

Piston top land height

$m$

$L$

Connecting rod length

m

$\dot{m}$

Mass flow rate

$\mathrm{kg} / \mathrm{s}$

M

Mass in a control volume

$k g$

$p_{a}$

Gas pressure in combustion chamber

$N / m^{2}$

$p_{c}$

Cavitation vaporisation pressure

$N / m^{2}$

$p_{e}$

Elastic (tension) ring pressure

$N / m^{2}$

$p_{g}$

Gas pressure behind the ring

$N / m^{2}$ 


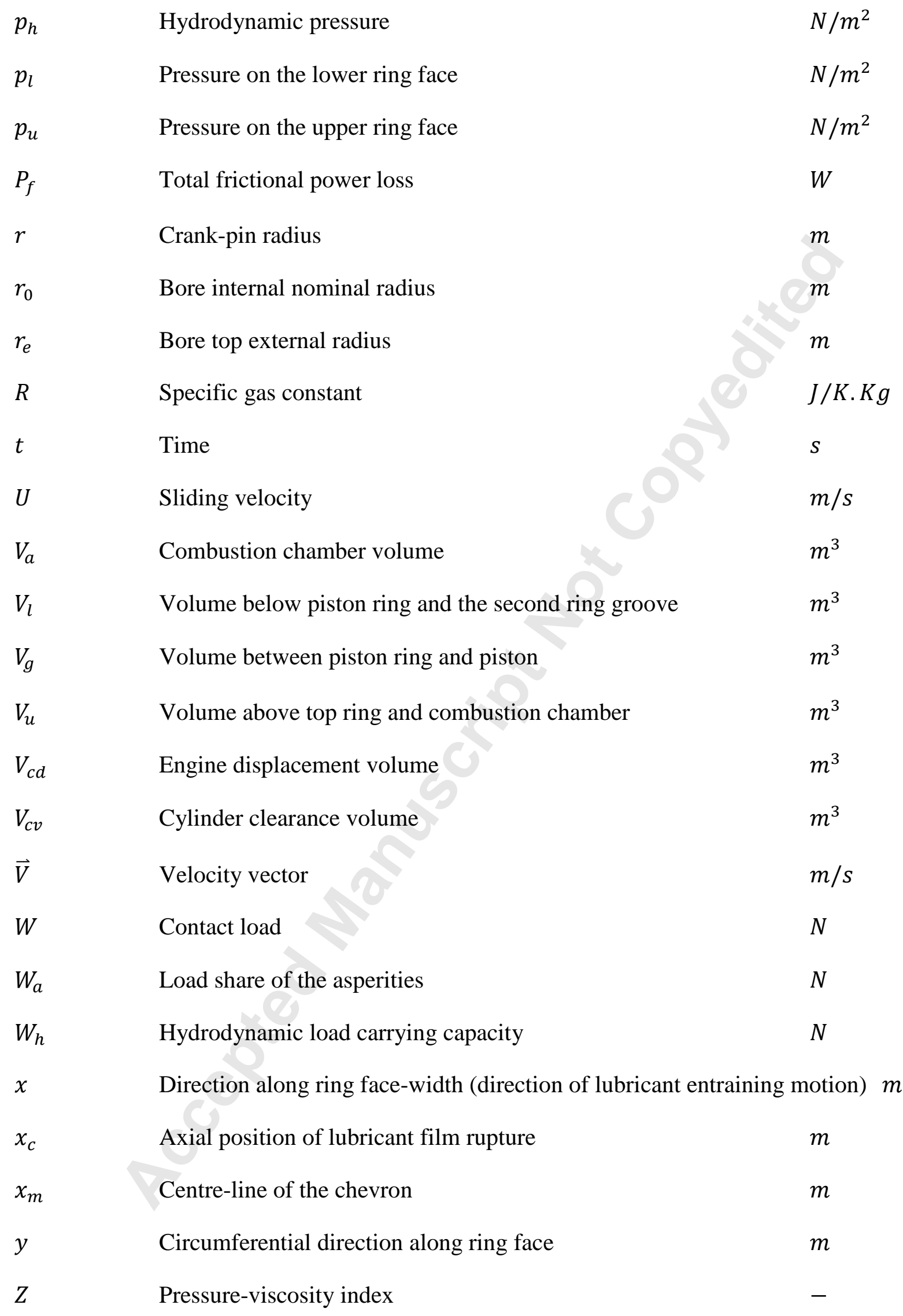

\section{Greek symbols}


$\alpha$

$\beta$

$\gamma$

$\varepsilon$

$\eta$

$\eta_{0}$

$\eta_{g}$

$\theta_{0}$

$\theta_{a}$

$\theta_{c}$

$\theta_{e}$

$\theta_{g}$

$\theta_{p}$

$\theta_{u}$

$\kappa$

$\lambda$

$\rho$

$\rho_{0}$

$\sigma$

$\xi$

$\tau$

$\tau_{0}$

$\chi$

$\omega$
Piezo-viscous parameter

Thermo-viscous parameter

Ratio of specific heat capacities

Lubricant thermal expansion coefficient

Lubricant effective viscosity

Lubricant viscosity at ambient conditions

Viscosity of gas flowing from or to the combustion chamber

Initial (bulk) lubricant temperature

Combustion chamber gas temperature

Initial assumed gas temperature at compression stroke

Effective lubricant temperature

Piston ring back temperature

Initial assumed gas temperature at power stroke

Temperature above top ring and combustion chamber

Average radius of curvature of asperities

Stribeck oil film parameter

Lubricant density

Lubricant density at ambient conditions

RMS roughness of contiguous surfaces

Number of asperities per unit contact area

Viscous shear stress

Eyring shear stress

Adjusting numerical parameter

Crankshaft angular velocity $m^{2} / N$

$1 / K$

$1 / K$

N. $s / m^{2}$

N. $s / m^{2}$

N. $s / m^{2}$

K

K

K

K

K

K

K

$m$

$\mathrm{kg} / \mathrm{m}^{3}$

$\mathrm{kg} / \mathrm{m}^{3}$

$m$

$1 / m^{2}$

$M P a$

$M P a$

$\mathrm{rad} / \mathrm{s}$

\section{Introduction}

Fuel efficiency and reduction of emissions are key drivers for the modern automotive internal combustion (IC) engine development. Parasitic frictional losses produced by the piston 
compression ring- cylinder liner contact account for 2-5\% of input fuel energy according to Andersson [1]. With the increasingly stringent legislations, the adverse effect of emissions mostly due to intrinsic inefficiency of IC engines and the growing scarcity of conventional cheaper fuels, this level of parasitic loss from such a small conjunction is not sustainable.

In general, a significant effort is directed towards mitigating the parasitic losses, including the associated errant dynamics. These include the pervading light-weight powertrain concept. Other palliation routes include the lowering of lubricant viscosity, introduction of wearresistant and low friction coatings and surface texturing (e.g. Etsion and Sher [2] and HowellSmith et al [3]). All these palliative actions can introduce some drawbacks, such as excessive ring dynamics, oil loss and blow-by (Tian et al [4] and Baker et al, [5]), reduced load carrying capacity (particularly with the same engine oil in other higher loaded conjunctions such as the cam-follower pair), as well as cavitation (Chong et al [6], Shahmohamadi et al [7]). Therefore, analysis of compression ring-cylinder liner conjunction is a multi-variate and arguably one of the most complex problems in tribo-dynamics.

The piston compression ring-cylinder liner contact experiences a transient regime of lubrication due to the variable nature of contact kinematics and the applied contact load in the various strokes of the IC engine. Therefore, a universally effective palliative measure for all parts of the engine cycle and under various driving conditions cannot be assured. At piston reversals (at the top dead centre, TDC and the bottom dead centre, BDC), there is momentary cessation of lubricant entrainment into the contact. This combination invariably results in mixed or boundary regimes of lubrication, where the direct contact of the surfaces at asperity level is encountered. There is also significant ring elastodynamic behaviour in approaching the TDC in order to seal the combustion chamber [8-9], this being the primary function of the compression ring. In turn, the ideal conformance of the ring to the liner surface can result in increased friction. In other instances during the piston cycle, mostly a hydrodynamic regime of lubrication has been predicted and also noted through measurements [10-13]. These observations, of course, are of a general nature as in reality the bore is not a right circular cylinder as manufactured and fitted, and undergoes significant transient thermo-mechanical distortions in service [14]. Therefore, the conjunctional gap between the ring and the liner may experience a mixed regime of lubrication almost at any part of the cycle. However, in general, worst tribological conditions are often encountered at TDC reversal, in transition from the compression to the power stroke in a 4-stroke engine. This has been predicted through numerous numerical analyses [1,2,6,7,10-14], which include varying degrees of complexity, some of which have shown good agreement with the various experimental measurements under different engine operating conditions [2,13].

Direct in-situ measurement of friction, using the floating liner method provides the best opportunity for determination of friction under various engine running conditions [15-18]. Those reported by Gore et al [18] on a high performance motocross motor-bike engine indicate that boundary interactions occur at the aforementioned TDC reversal and account for a significant proportion of in-cycle frictional losses of ring-liner contact. Styles et al [19] predict the same trend for a V12 high performance niche OEM vehicle, taking into account precise measurement of physical, topographical and shear characteristics of coated surfaces, 
evolving through the process of ring wear. They showed that $30 \%$ of the generated friction in an engine cycle can be attributed to the TDC reversal in transition from the compression to the power stroke. The prevalent mixed regime of lubrication in this region highlights the importance of viewing the problem as a lubricant-surface system, in which the role of surface topography is very significant.

For conjunctions with poor contact kinematics and/or high loads a growing area of interest has been the role that introduced surface features (widely referred to as surface textured patterns) can play in the retention of micro-reservoirs of lubricant or encourage lubricant entrainment through micro-wedge effect and/or pressure perturbations through microhydrodynamics. A review of literature on surface texturing is provided by Etsion [20], who describes the recent developments in laser surface texturing, noting that Ronen et al [21] predicted a potential savings of up to $30 \%$ in the case of piston ring application through numerical analysis. The results of Ronen et al [21] showed that by optimising the texturing relatively large reductions in friction can potentially be achieved. Yu et al [22] also reported the beneficial effect of texturing during sudden changes of speed in mechanical face seals. Pettersson and Jacobson [23] reported similar findings for the reciprocating ring/roller contact in hydraulic motors. For the specific case of piston-cylinder system, Rahnejat et al [24] observed a decrease of $2-4 \%$ in friction through the use of laser-ablated curvilinear chevron features on the surface of advanced coated cylinder liners in the vicinity of the TDC under normal engine operating conditions. The underlying micro-hydrodynamic effect was shown for the same case through detailed numerical analysis for the piston skirt-to-cylinder liner contact [3]. Etsion and Sher [2] and Etsion [25] also reported reduction in in-cylinder friction using laser textured dimple patterns. Similar improvements to tribological conditions have also been noted for other conjunctions such as for journal bearings, for example experimentally by Morris et al [26] and numerically by Jiang et al [27]. Morris et al [26] noted significant improvements with low journal speed, which would otherwise yield a mixed regime of lubrication. At higher journal speeds, side leakage oil loss was noted as a potential drawback of texturing.

Therefore, optimisation of surface texture feature shape, geometry and pattern/distribution are important parameters which should be considered for specific applications. Kligerman et al [28] presented an analytical model and carried out a parametric study, showing preferable surface texture parameters for flat (un-profiled) piston rings. They advocated partial texturing of ring's inlet chamfered faces with a pattern of dimples. Ryk et al [29-31] investigated the effect of employing optimised textured patterns by Ronen et al [21] in slider rig test, designed to reproduce the sliding motion of piston ring/cylinder liner contact. They employed rings with relatively flat face-width and mildly chamfered edges. A relatively large reduction in friction was observed for both partial and fully textured patterns when compared with that of a flat untextured ring profile. These were in line with the predictions made by Ronen et al [21]. However, Ryk et al [30] recommended that a more sophisticated analysis should include comparisons with real barrel shaped untextured ring profile. The implementation of the partially textured flat face rings in the real engine conditions by Etsion and Sher [2] has nevertheless shown that the textured flat face rings out-perform the untextured barrel shaped 
ones in terms of BSFC by $\sim 1$ to $4 \%$ depending on the engine loading and speed conditions. Checo et al [32] also investigated the effect of surface texturing with a number of generated ring profiles. They found that as the ring's radius of curvature increased a greater benefit was accrued. This indicated that a ring with an almost flat contacting face-width would be the optimal, as was also noted by Kligerman et al [28]. However, the study did not take into account any asperity interactions in the determination of generated friction, which would be important at reversal points [18,19]. Rahmani et al [33-34] used an analytic method to optimise the feature type and pattern for a flat sliding ring. They showed that for such geometry a dimple feature of certain depth and spacing ratio yielded optimum conditions. On the other hand, for a flat sliding strip, Costa and Hutchings [35] showed features in the form of chevron with certain geometry and distribution can outperform the dimples. A parametric numerical analysis by Morris et al [36] showed that an optimum distribution of similar chevrons with successive rows of counter-orientation yielded the optimum microhydrodynamic effect. The experimental tests carried out using a floating plate slider bearing verified their numerical findings. Although the applied conjunctional load and sliding velocity was representative of ring-liner contact at the TDC reversal, the controlled experiments under laboratory conditions with a slider bearing are rather different to those encountered by Gore et al [18] with a floating liner in a real engine.

This paper provides numerical solution for mixed-hydrodynamics of piston compression ringcylinder liner conjunction for a high performance motocross motorbike engine. A blow-by model is also developed and incorporated into the analysis for accurate prediction of pressure boundary conditions. The results are compared with in-situ real-time measurements of friction from a floating liner (without cross-hatched honing) fitted into the engine cylinder. Very good agreement is obtained between the predictions and the experimental measurements under real engine operating conditions. The verified model is then extended to include optimal chevron patterns described by Morris et al [36] to determine the potential application of the findings under real fired engine operating conditions.

\section{Theory}

\subsection{Hydrodynamic conjunction}

The piston compression ring-cylinder liner conjunction (Figure 1) operates transiently across a broad spectrum of regimes of lubrication, from hydrodynamics to mixed and onto direct boundary interactions. Lubricant is entrained into the gap between the piston ring and the cylinder liner through hydrodynamic wedge effect and provides for the main load carrying capacity. At low speeds of entraining motion such as those encountered at the top dead centre reversal, insufficient hydrodynamic pressures are generated. Thus, some of the applied load is carried by the interaction of asperity pairs on the counterfaces. The hydrodynamic load carrying capacity is obtained by determining the generated hydrodynamic pressures using Reynolds equation:

$$
\frac{\partial}{\partial x}\left(\frac{\rho h^{3}}{6 \eta} \frac{\partial p_{h}}{\partial x}\right)+\frac{\partial}{\partial y}\left(\frac{\rho h^{3}}{6 \eta} \frac{\partial p_{h}}{\partial y}\right)=U \frac{\partial}{\partial x}(\rho h)+2 \frac{\partial}{\partial t}(\rho h)
$$


where, $U$ is the sliding speed of the ring relative to the liner in the $x$-direction (Figure 1 ). A fully flooded inlet is assumed.

Assuming no instantaneous relative motion of the ring with respect to its retaining groove, such as ring flutter or twist, then the ring sliding speed is obtained as [37]:

$$
U \approx r \omega\left(\sin \omega t+\frac{r}{2 L} \sin 2 \omega t\right)
$$

where, the sliding speed includes inertial dynamic motions up to the second engine order $(2 \omega)$. The applied load is a combination of gas pressure loading $F_{g}$, acting behind the inner rim of the ring and the ring's elastic tension $F_{e}$, both of which press the ring normal to the surface of the liner (Figure 1). Any ring twist is ignored in the current analysis.
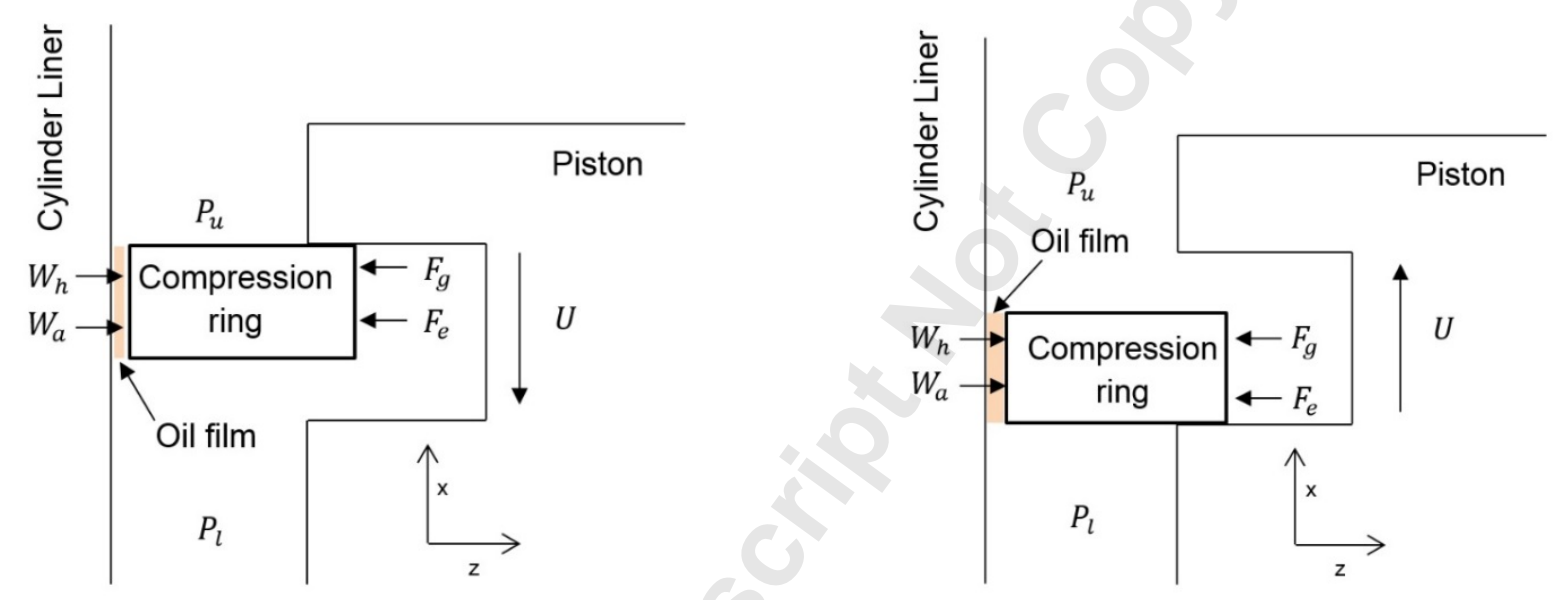

Figure 1: Contact configuration

\subsection{Film shape}

Ma et al [38], Akalin and Newaz [10-11] and Mishra et al [39] have shown that the generated conjunctional pressures in the partially conforming compression ring-bore contact are insufficient to cause any localised contact deformation. Therefore, the oil film thickness in the contact may be described as (see Figure 2):

$h(x, y, t)=h_{m}(t)+h_{s}(x, y)+h_{t}(x, y)$

where, $h_{m}$ is the minimum film thickness, $h_{s}$ is the ring face profile and $h_{t}$ describes the profile of introduced surface features which in this case are the profile of the laser etched chevrons introduced on the cylinder liner in particular locations. In the current analysis any ring elastodynamic modal behaviour is ignored. Furthermore, the overall geometry of the bore is considered to be a right circular cylinder. Baker et al [5] have shown that the top compression ring undergoes modal deformation to conform well to an assumed right circular cylindrical liner in order to perform its desired sealing function. Therefore, the approximate representation made here is quite representative of the ring conditions at the TDC reversal. 
Clearly, the prevailing regime of lubrication would be mixed. Therefore, for the rough topography Patir and Cheng [40] average flow model can ideally be used. However, the available flow factors for such a model are those for surfaces with a Gaussian distribution of asperities. The cylinder liner is cross-hatch honed, where the topography does not conform to a Gaussian distribution in practice [41]. This point is described later.

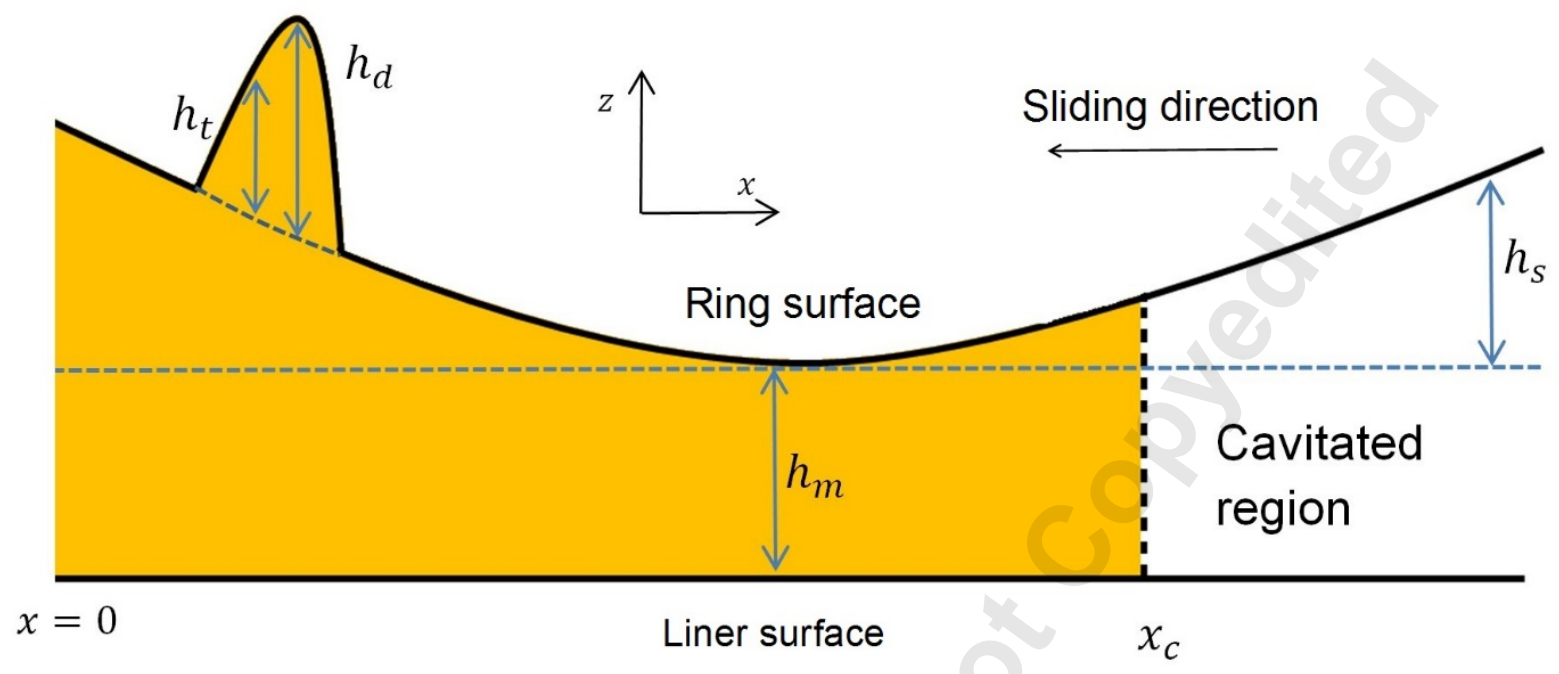

Figure 2: Film shape for contact with surface texture

\subsection{Ring face profile}

The profile of the ring face, $h_{s}$ in equation (3) is modelled as only varying in the axial $x$ direction; i.e. the direction of lubricant entraining motion. The axial ring profile is an important factor for the entrainment of the lubricant into the conjunction through hydrodynamic inlet wedge effect [42].

For the purpose of numerical analysis, the ring profile was measured using an Alicona Infinite Focus Microscope with a measurement resolution of $1 \mathrm{~nm}$. A polynomial fit of the measurement data is shown in Figure 3. 


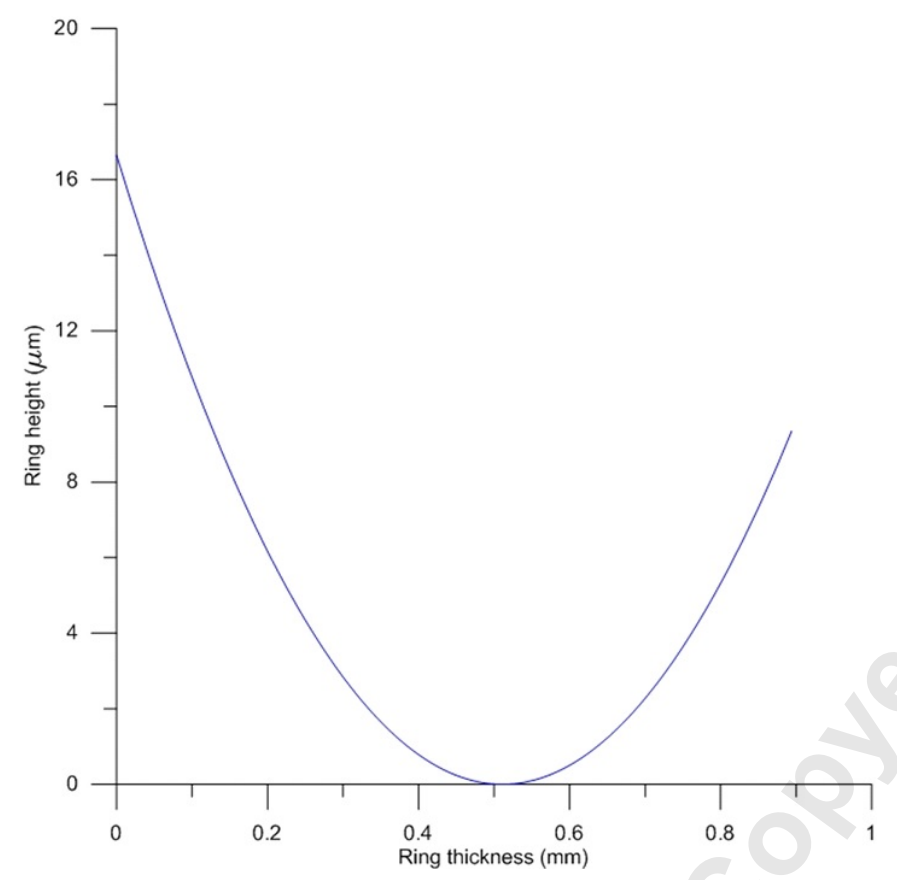

Figure 3: Polynomial fit for measured ring face profile shape

\subsection{Numerical reconstruction of laser textured chevrons}

The surface features (chevrons) are modelled so that their inclusion angle, length, width and thickness can all be readily altered. These are based on the measurements made using the Infinite Focus Microscope. Additionally, inter-spacing between chevrons in a row in the $y$ direction (the transverse direction) and separation of successive rows in the $x$-direction (the direction of sliding) are taken into account as shown in Figure 4. The start and termination points of the textured region are also defined.

It has been shown by Morris et al [39] that textured features, using a fibre laser produces a texture cross-sectional profile similar to that of a parabola. Therefore, the chevrons were modelled with a parabolic cross-sectional profile. The data presented in Table 1 provides the information regarding the geometry of the two surface texture features modelled in the current study, both of which are similar to those presented by Costa and Hutchings [35], where density refers to the percentage of the surface area covered by textures.

Table 1: Chevron surface texture feature dimensions

\begin{tabular}{lcccccc}
\hline $\begin{array}{c}\text { Chevron } \\
\text { Type }\end{array}$ & $\begin{array}{c}\text { Depth } \\
(\mu \mathrm{m})\end{array}$ & $\begin{array}{c}\text { Angle } \\
\left({ }^{\circ}\right)\end{array}$ & $\begin{array}{c}\text { Thickness } \\
(\mu \mathrm{m})\end{array}$ & $\begin{array}{c}\text { Density } \\
(\%)\end{array}$ & $\begin{array}{c}\text { Width } \\
(\mu \mathrm{m})\end{array}$ & $\begin{array}{c}\text { Length } \\
(\mu \mathrm{m})\end{array}$ \\
\hline $\begin{array}{l}\text { Costa \& } \\
\text { Hutchings }\end{array}$ & 5 & 120 & 30 & $7.0 \%$ & 450 & 130 \\
[32] & & & & & & \\
$\begin{array}{l}\text { Pattern A } \\
{[33]}\end{array}$ & 3 & 120 & 30 & $11.5 \%$ & 370 & 106 \\
\hline
\end{tabular}




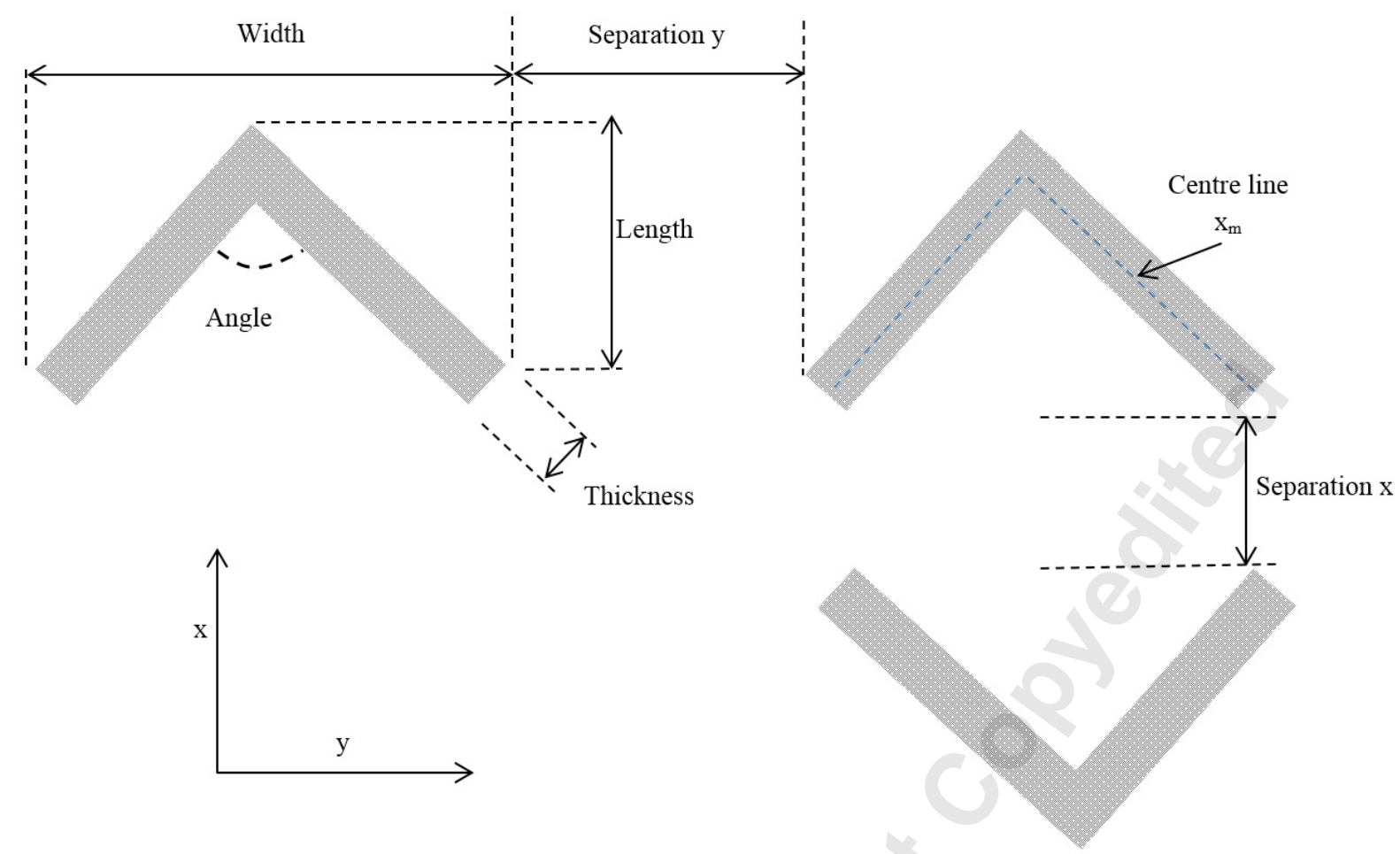

Figure 4: A schematic of geometry and distribution parameters of chevrons

If $l_{c}$ is the thickness of a chevron, $h_{d}$ its depth at its centre-line location and $x_{m}$ the position of the centre-line of the chevron cross-sectional width, then a chevron profile can be described as:

$$
\left(\frac{x-x_{m}}{l_{c} / 2}\right)^{2}+\frac{h_{t}}{h_{d}}=1
$$

\subsection{Lubricant rheology}

The lubricant bulk rheological state comprising viscosity and density are affected by pressure and temperature. The current analysis includes the thermal and piezo-viscous behaviour of the lubricant. The lubricant dynamic viscosity is calculated at each crank angle position as given by Houpert [43]:

$$
\eta=\eta_{0} \exp \left\{\left(\ln \eta_{0}+9.67\right)\left(\left[\frac{\theta_{e}-138}{\theta_{0}-138}\right]^{-S_{0}}\left[1+5.1 \times 10^{-9}\left(p-p_{a t m}\right)\right]^{Z}-1\right)\right\}
$$

where, $Z$ and $S_{0}$ are characteristics specific to particular lubricants:

$$
S_{0}=\frac{\beta\left(\theta_{0}-138\right)}{\ln \eta_{0}+9.67}, \quad Z=\frac{\alpha}{5.1 \times 10^{-9}\left(\ln \eta_{0}+9.67\right)}
$$

in which, $\alpha$ and $\beta$ are the piezo-viscous parameter and thermos-viscous parameter respectively.

The variations of density with pressure and temperature can be defined as follow [44-45]: 


$$
\rho=\rho_{0}\left[1+\frac{6 \times 10^{-10}\left(p-p_{a t m}\right)}{1+1.7 \times 10^{-9}\left(p-p_{a t m}\right)}\right]\left[1-\varepsilon\left(\theta_{e}-\theta_{0}\right)\right]
$$

where, $\varepsilon$ may be considered as the lubricant's thermal expansion coefficient.

\subsection{Boundary conditions}

A fully flooded inlet is assumed and the following boundary conditions are used along the axial $x$-direction of the contact. The boundary conditions depend upon the pressures at the top and bottom faces of the ring. These pressures are dependent on the residing position of the ring during the various engine strokes (Figure 1). The pressures at inlet and outlet sides of the ring/liner contact are shown in Figure 1.

The upper pressure $P_{u}$ is the combustion chamber pressure and the lower pressure $P_{l}$ is assumed to be at the atmospheric pressure. These boundary pressures are used in a gas flow model to determine the pressure acting behind the inner rim of the ring, which contributes to the instantaneous applied load.

In reality, $P_{l}$ is usually higher than the atmospheric pressure, being the inter-ring pressure between the top compression ring and the scrapper ring for the 2-ring (compression and oil control rings) engine configuration studied here. The contact exit boundary conditions are assumed to be those of Swift -Stieber, thus:

$p_{h}\left(x_{c}, y\right)=P_{c} \quad$ and $\quad\left(d p_{h} / d x\right)_{x=x_{c}}=0$

These boundary conditions determine the position of lubricant film rupture, $x_{c}$ beyond which a cavitation region occurs. This exit boundary has been shown to give a good correlation with the experimental results particularly in the study of the piston ring-liner conjunction by Arcoumanis et al [46]. An analysis by Chong et al [6], using the Elrod's cavitation algorithm takes into account the effect of cavitation [47]. However, the effect of cavitation is best described if the multiphase nature of the flow at this region is understood well. This would require the solution of multi-phase flow using Navier-Stokes equations, vapour transport and energy equations (Shahmohamadi et al [7]). The effect of cavitation on load carrying capacity and generated conjunctional viscous friction is more significant in engine bearings. This effect is ignored in the current analysis.

\subsection{Gas flow model}

A gas flow model is used in this study to determine the pressure acting behind the inner rim of the compression ring. The model is based on that reported by Baker et al [9] who modified the analysis techniques of Gulwadi [48] and Ruddy et al [49].

A cross-section of the compression ring-cylinder liner contact and the surrounding control volumes is shown in Figure 5. The pressure in the control volume 1 is assumed to be the same as the combustion chamber pressure, $P_{u}$, obtained using a blow-by meter under engine testing conditions. The pressure in the control volume $3 ; P_{l}$ is assumed to be at the crankcase pressure (as already noted, and for the purpose of the current study this is assumed to be at 
the atmospheric pressure). Furthermore, it is assumed that the ring does not float or flutter within its retaining groove (i.e. either pressed against the top or the bottom groove lands, depending on the applied control volume pressures and the internal forces acting upon the ring). In practice, the ring commences to move to the top groove land when the piston is at mid-span in the compression stroke and remains there well past the detonation point $[8,50]$.

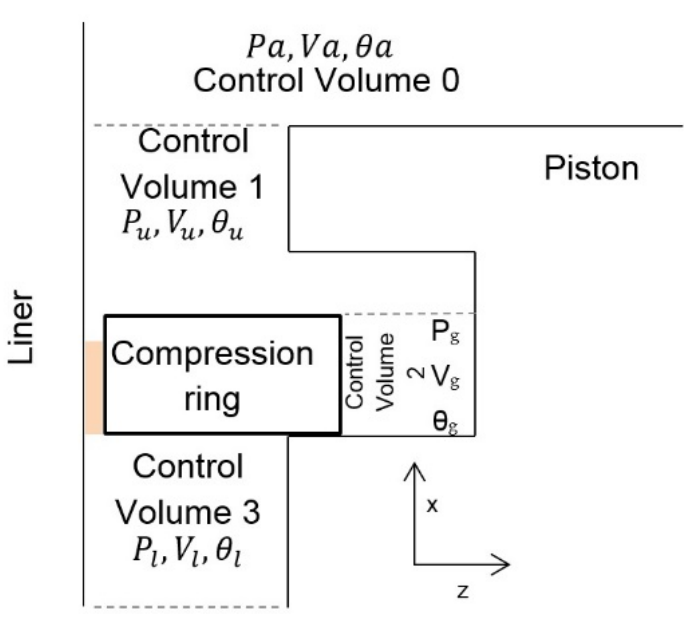

Case 1

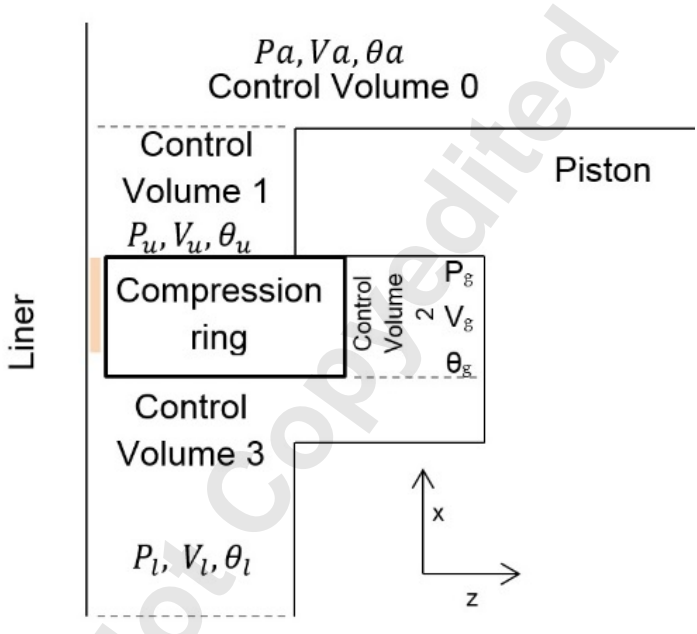

Case 2

Figure 5: The control volumes for the gas blow-by model

An iterative method, based on the $4^{\text {th }}$-order Runge-Kutta method, is used to calculate the pressure and temperature. At the start of the process, an initial temperature for each control volume is assumed, based on given typical values in [50]. The temperature variation in each control volume at each stroke due to volumetric variations is given by [50]:

For the compression stroke:

$\theta_{a}=\theta_{c}\left(\frac{V_{c v}+V_{c d}}{V_{c c}}\right)^{\gamma-1}$, where $\gamma=1.3, \theta_{c}=80^{\circ} \mathrm{C}$

For the power stroke:

$\theta_{a}=\theta_{p}\left(\frac{V_{c v}}{V_{c c}}\right)^{\gamma-1}$, where $\gamma=1.3, \theta_{p}=1700^{\circ} \mathrm{C}$

And finally for the exhaust and intake strokes:

$\theta_{a}=109^{\circ} \mathrm{C}$

where, $V_{c c}$ is the volume in the combustion chamber, $V_{c v}$ is the cylinder clearance volume, $V_{c d}$ is the cylinder displacement volume and $\gamma$ is the specific heat capacity ratio.

In this analysis the temperature in the control volumes 1,2 and 3 is assumed to be that of the liner. A more accurate estimate of these may be obtained through thermodynamic analysis. 
Knowing the volume, pressure and temperature for each control volume, the gas mass in each control volume can easily be calculated using the ideal gas law:

$m_{g}=\frac{P_{g} V_{g}}{R \theta_{g}}$

Then, the mass flow rates between the control volumes are initially calculated at a given crank angle, based on the initial state (pressure) of each control volume. The flow rate between two control volumes can be calculated using Reynolds equation as suggested by Gulwadi [48]. For example, the mass flow from control volumes 1 to 2 can be obtained as:

$\dot{m}_{12}=\frac{A_{1} h_{1}^{2}}{24 l_{1} \eta_{g} R \theta_{g}}\left(P_{u}{ }^{2}-P_{g}{ }^{2}\right)$

where, $A_{1}$ is the cross-sectional area of the control volume $1, h_{1}$ is the distance between the liner and the piston top land, $l_{1}$ is the top land height, $P_{g}$ is the initial pressure assumed in the control volume 2. The same methodology can be used to determine the mass flow rate between all the desired control volumes.

Through the principle of conservation of mass the alteration of mass in each control-volume, the new gas mass at each control volume is calculated as follow:

$m_{\text {new }}-m_{\text {old }}=\left(\dot{m}_{\text {in }}-\dot{m}_{\text {out }}\right) \Delta t$

With the new mass obtained for the control volume 2, the correct pressure value is then calculated from the ideal gas law. This is repeated until a balance between pressure and mass in each control volume is achieved.

As the piston moves to the next crank angle, the same procedure is repeated to obtain the correct pressure at the inner rim of the ring; i.e. the control volume 2, for each crank angle.

\subsection{Contact forces}

In the radial plane the ring is subjected to a combination of two outward forces; the ring tension (elastic force), $F_{e}$, and the gas force acting upon the inner rim of the ring, $F_{g}$. The ring tension force, $F_{e}$ is calculated based on the ring end gap size described in [51]. The gas force, $F_{g}$ on the other hand is obtained from the gas flow analysis explained in the previous section using the measured in-cylinder gas pressure shown in Figure 7. Further details on calculating the load applied by the ring can be found in [14].

The measured combustion pressure and the calculated gas pressure acting on the ring are shown in Figure 7.

The aforementioned contact forces strive to conform the ring to the liner surface and are opposed by the hydrodynamic film reaction and any contribution due to the direct contact of asperities on the opposing contacting surfaces, thus:

$W=W_{h}+W_{a}$ 
where,

$W_{h}=\int_{0}^{l} \int_{0}^{b} p_{h} d x d y$

The load share carried by the asperities can be written as (Greenwood and Tripp, [52]):

$W_{a}=\frac{16 \sqrt{2}}{15} \pi(\xi \kappa \sigma)^{2} \sqrt{\frac{\sigma}{\kappa}} E^{\prime} A F_{5 / 2}(\lambda)$

The dimensionless roughness parameter $\xi \kappa \sigma$ and typical asperity slope $\sigma / \kappa$ [42] are obtained through topographical measurements. A statistical function $F_{5 / 2}(\lambda)$ is used to model the assumed Gaussian distribution of asperities as a function of the Stribeck oil film ratio: $\lambda=h(x, y, t) / \sigma$. This function was originally described by Greenwood and Tripp [52], who assumed a Gaussian distribution of asperities. The cross-hatch honed surface of cylinder liners used in practice do not comply with a Gaussian distribution of asperities. However, cross-hatching leads to the formation of a plateau, the "peakiness" of the surface topography upon this plateau conform closely to a Gaussian distribution prior to running-in condition. Therefore, the analysis reported here confines to such conditions. A $5^{\text {th }}$-order polynomial approximation of this function is given in [14,42].

The topography of the usual cross-hatch plateau honed cylinder liner surfaces does not conform to a Gaussian distribution. This is the reason for the use of a floating liner which is not cross-hatched for the purpose of this investigation.

\subsection{Method of solution}

Reynolds equation was discretised using Finite Difference Method (FDM). A PointSuccessive Over-Relaxation (PSOR) method was used to obtain the pressure distribution. The convergence criterion for the pressure was set to $10^{-5}$. To find the minimum film thickness a quasi-static load balance between the applied load due to gas pressure and ring elastic tension and the opposing hydrodynamic reaction and asperity load share was sought. At each iteration step, if the convergence criterion for the load balance, set at the tolerance limit of $10^{-3}$, was not achieved, then the minimum film thickness was updated. This process was continued until a load balance was achieved with errors below the given tolerance limits. The textured area has the dimensions $2 \mathrm{~mm}$ circumferentially and $0.894 \mathrm{~mm}$ in the axial direction of the cylinder. This area is discretised into $900 \times 900$ computation points in the $x$ and $y$ direction. Full details of the numerical method have already been published and can be found in [14].

\subsection{Friction and power loss}

During piston reversal a mixed regime of lubrication would be expected, comprising viscous shear of the lubricant, entrained into the conjunction, and any direct interactions of a portion of counterface asperities. Thus, the total friction becomes:

$f=f_{v}+f_{b}$ 
where, the viscous friction force is:

$f_{v}=\int_{0}^{l} \int_{0}^{b}\left| \pm \frac{h}{2} \vec{\nabla} p-\Delta \vec{V} \frac{\eta}{h}\right| d x d y$

It is assumed that boundary friction comprises two contributions. The first contribution is as a result of interaction of asperity pairs causing the formation of adhesive junctions, which need to be broken in order to maintain the sliding motion. If the pressure-induced shear strength of asperities is $\zeta$, then the friction as a result of direct asperity interactions is obtained as: $\zeta W_{a}$. For the formed ferrous surface oxide layer $\zeta=0.17$ (Teodorescu et al [53]).

The second contribution is due to a thin film of lubricant entrapped between the interspatial cavities of asperities. Briscoe and Evans [54] assume that such diminutive films act in nonNewtonian shear. For simplicity, one may assume that they are subject to the limiting Eyring shear stress, $\tau_{0}$, thus their frictional contribution is $\tau_{0} A_{a}$, where $\tau_{0}=2 \mathrm{MPa}$ for the engine oil used in the current investigation. Hence, boundary friction is obtained as:

$f_{b}=\tau_{0} A_{a}+\zeta W_{a}$

The asperity contact area for an assumed Gaussian distribution of asperities is [52]:

$A_{a}=\pi^{2}(\xi k \sigma)^{2} A F_{2}(\lambda)$

where, the statistical function $F_{2}(\lambda)$ originally described by Greenwood and Tripp [52] can be as approximated by a polynomial fit (for instance, see [14,42,53]).

Finally, the total conjunctional power loss becomes:

$P_{f}=f|U|$

\section{Model validation}

It is essential to validate the outlined predictive analysis against experimental data prior to prediction of performance of textured surfaces, which is the primary objective of this paper. For this purpose, experimentally acquired data from a floating liner fitted into a high performance single cylinder Honda CRF 450R motocross motorbike engine is used. Specifications for the employed engine are listed in Tables 2 and 3, as well as for the lubricant in Table 4. The floating liner device is suspended in the cylinder bore in such a way that the points of contact between the liner and any rigidly mounted components are intervened by a number of piezoelectric load cells (Figure 6). The liner is dragged by the motion of the piston assembly through the generated interfacial shear of a film of lubricant and any direct boundary interactions (total friction, $f$ ). The piezoelectric load cells measure the inertial dynamic force $(m a)$, which is only opposed by the generated friction and downward chamber pressure acting on the upper rim of the liner. Detailed description of the floating liner device is provided by Gore et al [55]. The advantage of this device is in the direct in-situ real time measurement of friction. The test engine uses a piston with 2 rings; a compression ring and an oil control ring. In order to be able to measure the contribution of the compression ring-liner conjunction to the overall piston-cylinder friction (comprising the 
conjunctions made between the piston skirt, compression ring and the oil control ring and the cylinder liner), it is necessary to be able to carry out engine tests with and without the compression ring. This necessitated the engine to be motored rather than fired and a piston of tighter nominal clearance be used.

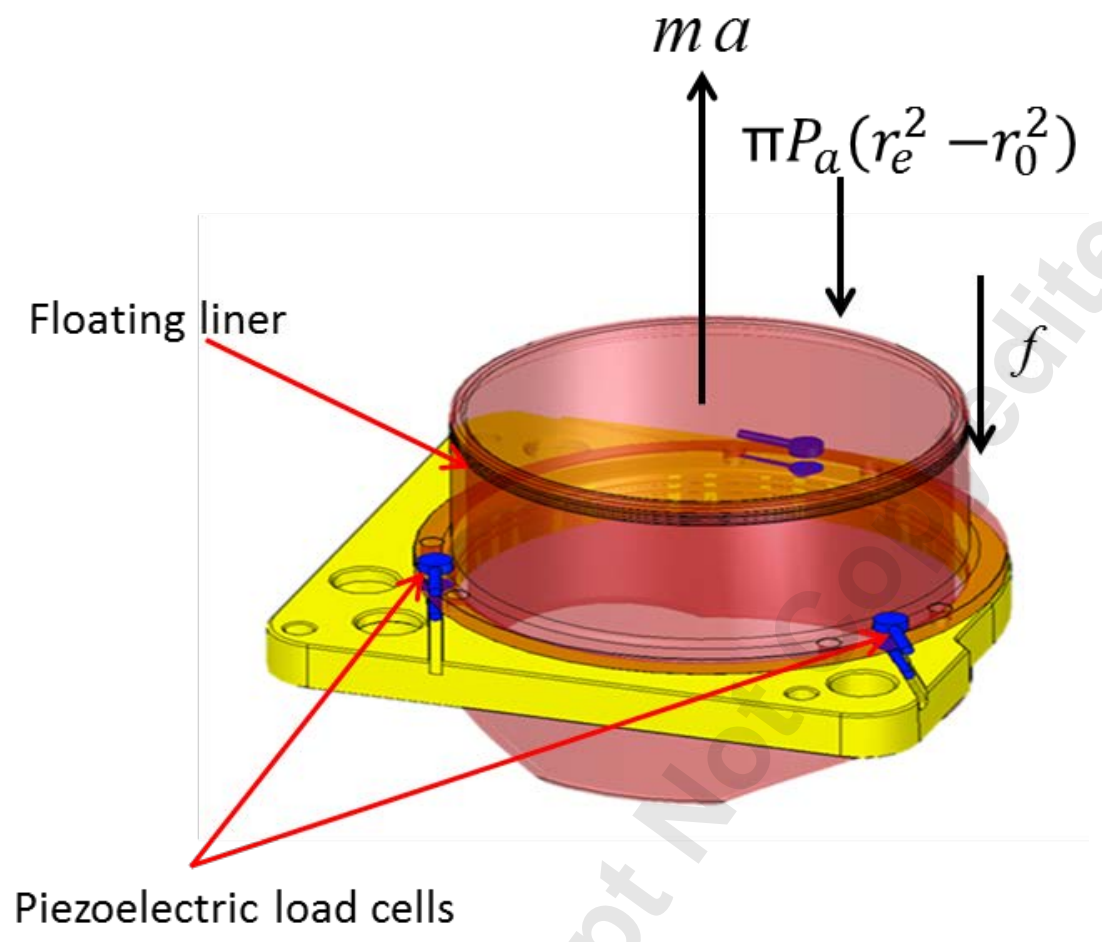

Figure 6: Measuring friction with a floating liner

Figure 7 shows the measured in-cylinder chamber pressure using a spark plug-type Kistler pressure sensor fitted into the chamber under motored condition with the engine speed of $3000 \mathrm{rpm}$. The sliding speed of the piston is also calculated from the output signal of a shaft encoder and shown in the figure. The compression ring back pressure, $P_{g}$, obtained using the gas flow model is also shown in the figure.

Table 2: Honda CRF450 Engine data

\begin{tabular}{lll}
\hline Parameter & Value & Unit \\
\hline Crank-pin radius, $r$ & 31.5 & $\mathrm{Mm}$ \\
Connecting rod length, $L$ & 107 & $\mathrm{Mm}$ \\
Bore nominal radius, $r_{o}$ & 48 & $\mathrm{Mm}$ \\
Ring face-width, $b$ & 1.15 & $\mathrm{Mm}$ \\
Ring thickness, $d$ & 3.5 & $\mathrm{Mm}$ \\
\hline
\end{tabular}


Table 3: Ring and liner mechanical properties Honda CRF450

\begin{tabular}{llc}
\hline \multicolumn{2}{c}{ Ring/Liner mechanical Properties } \\
\hline Liner material & Aluminium \\
Young's modulus of liner & 75 & $\mathrm{GPa}$ \\
material & 0.3 & - \\
Liner Poisson's ratio & Stainless steel \\
Ring material & 203 & $\mathrm{GPa}$ \\
Young's modulus for ring coating \\
material
\end{tabular}

Table 4: Lubricant properties Honda CRF450

\begin{tabular}{lll}
\hline Parameter & Value & Unit \\
\hline Lubricant & $849.7 @ 15^{\circ} \mathrm{C}, 833.8$ & $\mathrm{Kg} / \mathrm{m}^{3}$ \\
density & $@ 40^{\circ} \mathrm{C}$ & \\
Kinematic & $59.99 @ 40^{\circ} \mathrm{C}, 9.590$ & $\times 10^{-6} \mathrm{~m}^{2} \mathrm{~s}^{-1}$ \\
viscosity & $@ 100^{\circ} \mathrm{C}$ & \\
\hline
\end{tabular}




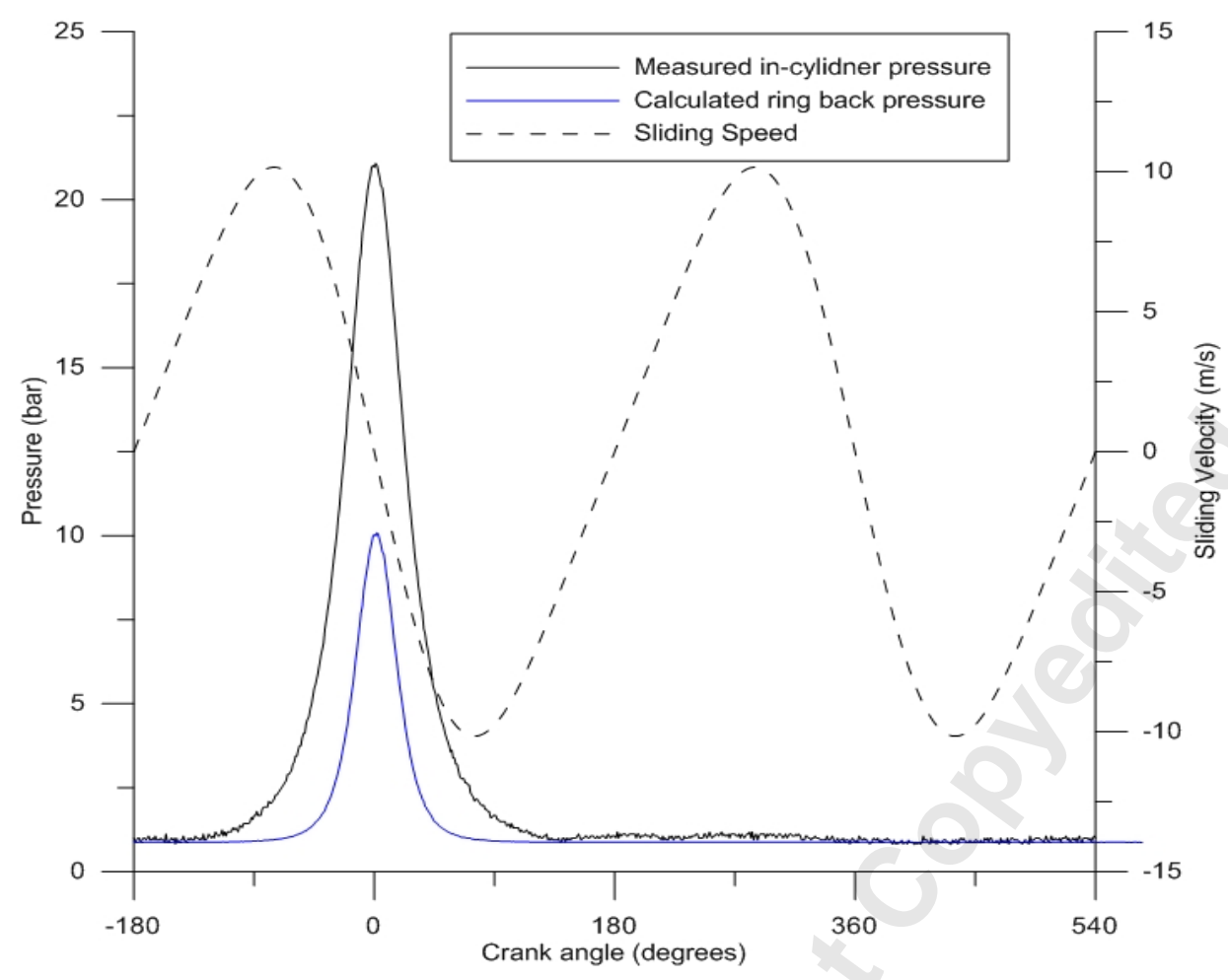

Figure 7: Motored data for speed and in-cylinder pressure for validation

Figure 8 shows the measured friction generated by the whole piston assembly, comprising the piston skirt, the oil control ring and the compression ring, as well as the case when the piston compression ring is removed (leaving just the skirt's and the oil control ring's contributions). The cylinder liner temperature is measured during the short testing time at $40^{\circ} \mathrm{C}$. A large number of tests were carried out. The friction traces in Figure 8 correspond to the average of these tests which showed good repeatability under controlled engine testing conditions. Of particular interest are the regions of high friction just prior to, and immediately after the piston reversal at the TDC. Direct measurements by other researchers for various engines and test rigs have also shown this region to account for the significant portion of in-cycle frictional losses [3,11,15-17,55]. Various numerical predictions have also shown the prevalent mixed and boundary regimes of lubrication in transition between the compression to power strokes at the TDC reversal $[5,12-14,19]$. Therefore, the experimental findings are in-line with previous measurements and predictions.

The observed differences between the two friction traces in Figure 8 correspond to the contribution of the compression ring. Owing to the presence of signal noise, as well as the difficulty to precisely line up these traces, two regions of interest are identified as shown in the figure. The average of the differences between the two traces in each region is deemed to provide a reasonable estimate of the frictional contribution of the compression ring conjunction alone. These can be compared with the numerical predictions with the current method, shown in Figure 9, which corresponds to the compression ring conjunction only. 


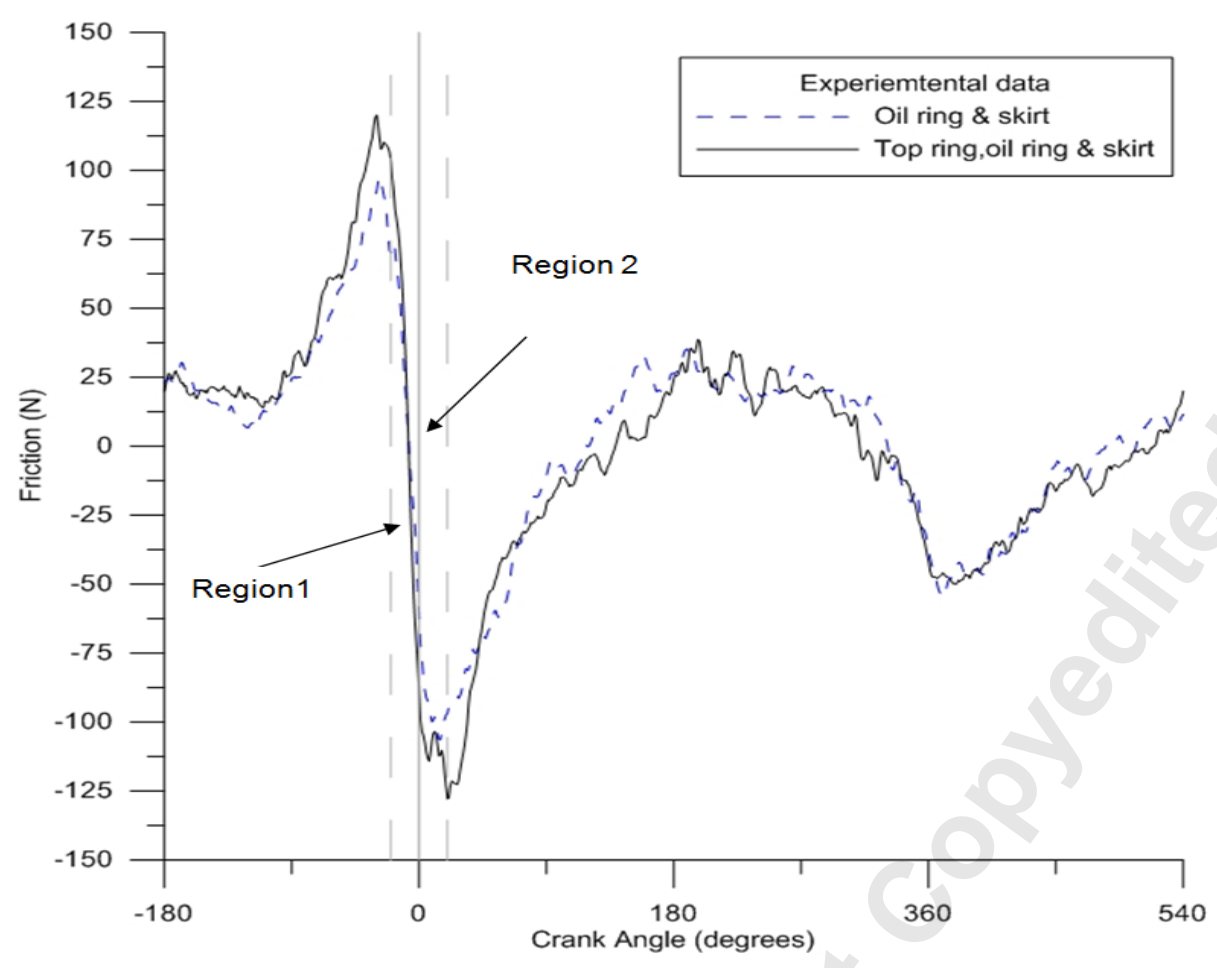

Figure 8: Experimental motored data at 3000 RPM with and without the top compression ring

Figure 9 shows the predicted frictional variation for a piston cycle of $720^{\circ}$ crank angles for the compression ring-liner conjunction. The comparison between the predictions and the averaged measured compression ring contributions in the two highlighted regions are shown in Figure 10.

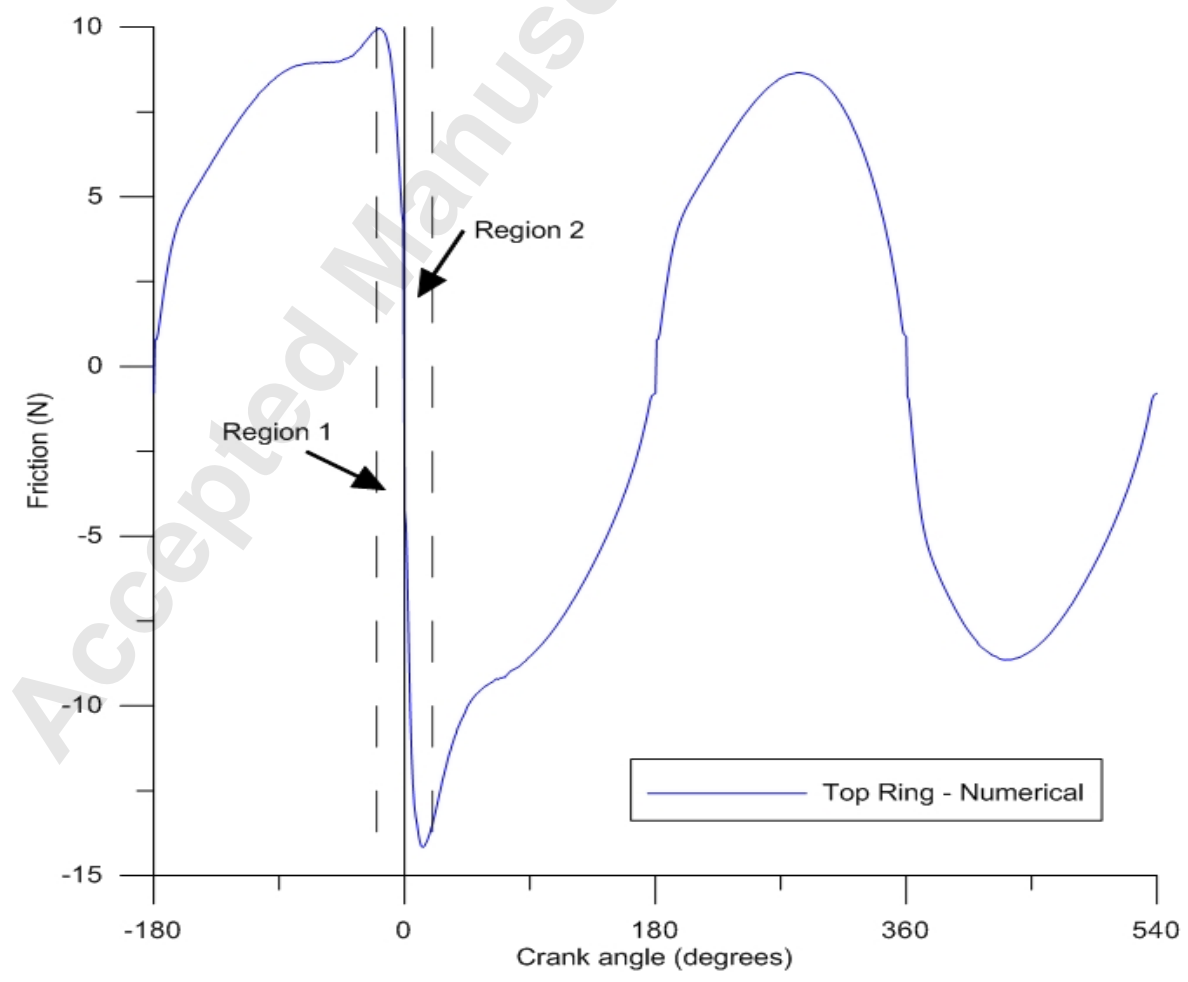

Figure 9: Numerical prediction of friction motored at $3000 \mathrm{rpm} 40^{\circ} \mathrm{C}$ 
Good agreement is achieved between the observed trends in predictions and the experimental measurements. This imparts a good level of confidence in the developed numerical method, which can be employed to predict any potential reduction in friction when surface textured patterns are introduced in the vicinity of TDC reversal (corresponding to the regions 1 and 2, highlighted in Figures 8 and 9) on the cylinder liner surface. Tests reported with curvilinear chevrons at such a location by Rahnejat et al [24] showed 2-4\% engine power gain under fired condition with the same engine used in this investigation. Preliminary testing and numerical predictions for simulated condition on a reciprocating flat floating plate test rig by Morris et al [36] showed friction reductions of the same order when using chevron textures of certain geometry, pattern and distribution.

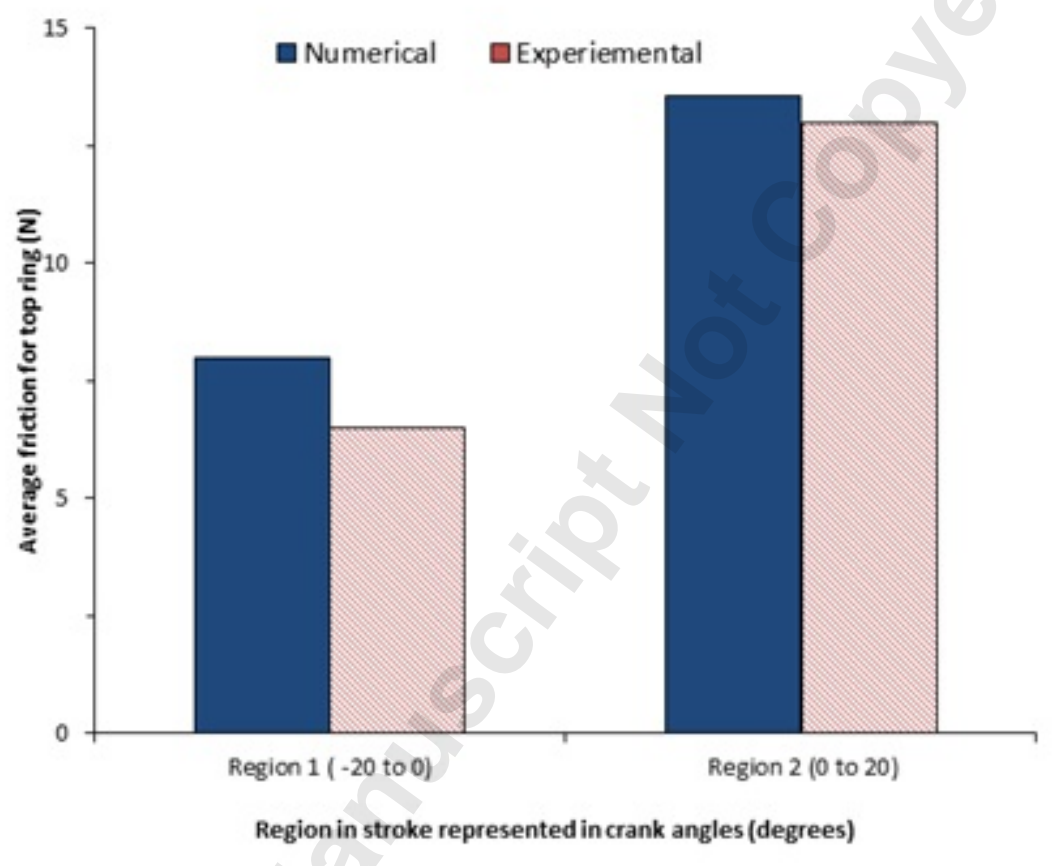

Figure 10: Comparison of numerical predictions and experimental results for motored engine at $3000 \mathrm{rpm}$ and $40^{\circ} \mathrm{C}$ for the regions before and after the TDC reversal

\section{Prediction of friction with a textured liner}

An assessment of friction reduction can be made with the validated method, prior to texturing of the floating liner device, which is an expensive process, given many parameters involved such as chevron geometry, pattern and distribution. Furthermore, the predictions are made for the case of the fired engine condition. Figure 11(a) shows the measured liner temperature at the various crank angle positions. Figure 11(b) shows the measured combustion curve for the engine speed of $3000 \mathrm{rpm}$ with partial throttle and the engine torque of $30 \mathrm{Nm}$. The pressure acting behind the compression ring, $P_{b}$ calculated using the gas flow model, is also shown in the figure, as well as the piston sliding speed. Therefore, Figure 11 provides the input for the analysis, but in this instance for the fired engine conditions. These data are different to their counterparts in Figure 7 which were used for the motored engine conditions. Clearly, the increased liner temperature and ring back pressure alter the contact load and lubricant 
rheological state, being more representative of the engine actual operation. Under fired conditions the compression ring cannot be removed.

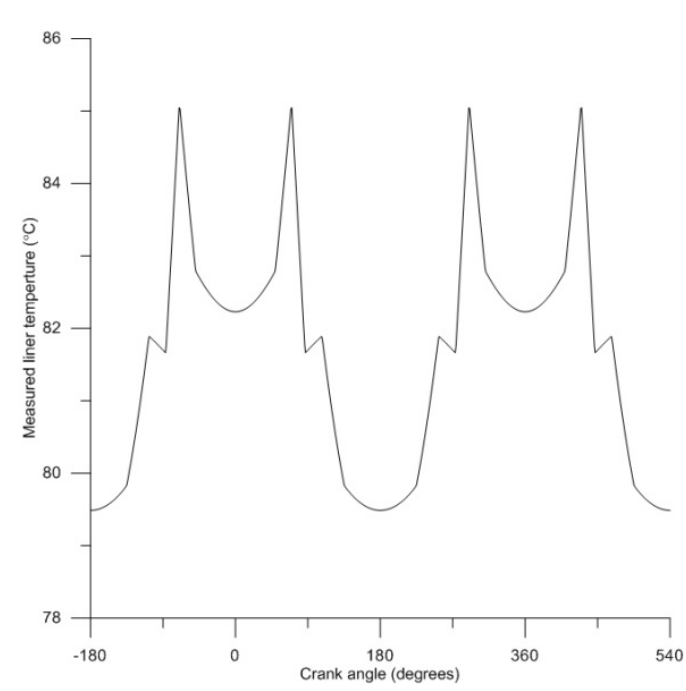

(a)

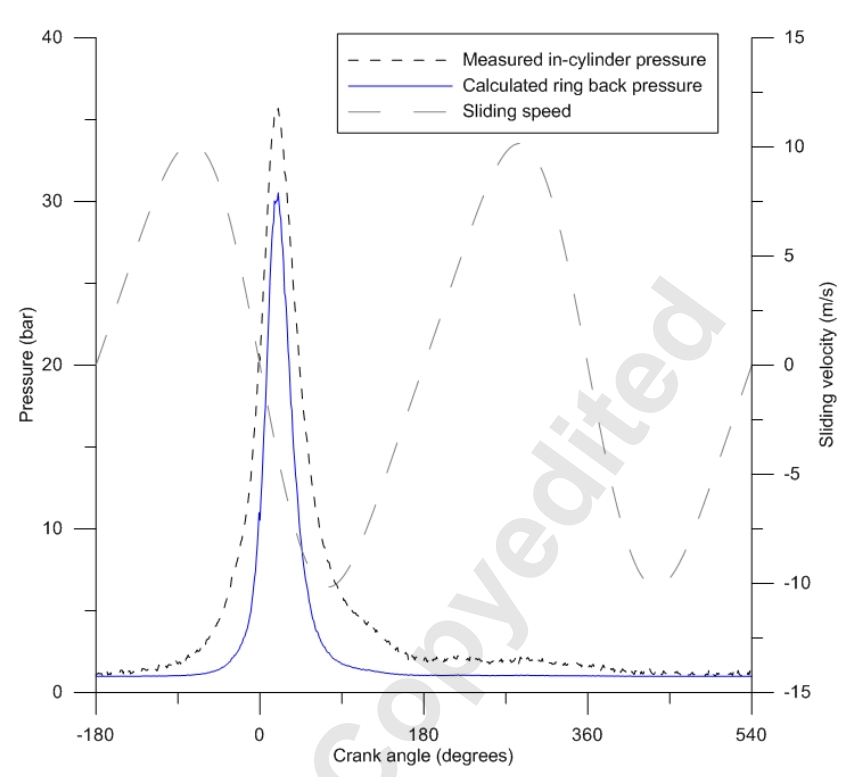

(b)

Figure 11: (a) Measured cylinder liner temperature (b) Measured in-cylinder combustion pressure for fired engine at $3000 \mathrm{rpm}$ with partial throttle (low load of $30 \mathrm{Nm}$ )

Two chevron texture forms and patterns shown in Figure 4 and described in Table 1 are used in the analysis. In both cases the depth of the chevron feature is varied from 1-3 $\mu \mathrm{m}$. The results of analysis are compared with un-textured liner surface of the same roughness.

Figure 12 shows the numerically predicted friction reduction produced by the chevron shaped surface textures of 1, 2 and $3 \mu \mathrm{m}$ in depth when compared with those of an un-textured liner. The results show that the "optimal" depth has changed from that found by Morris et al [36] ( $3 \mu \mathrm{m}$ for a slider bearing rig with a flat floating plate). Figure 12 also shows that the chevrons of $1 \mu \mathrm{m}$ depth are generally more effective particularly at higher lubricant temperature in a fired engine, which is not present in laboratory slider bearing rigs [36]. 


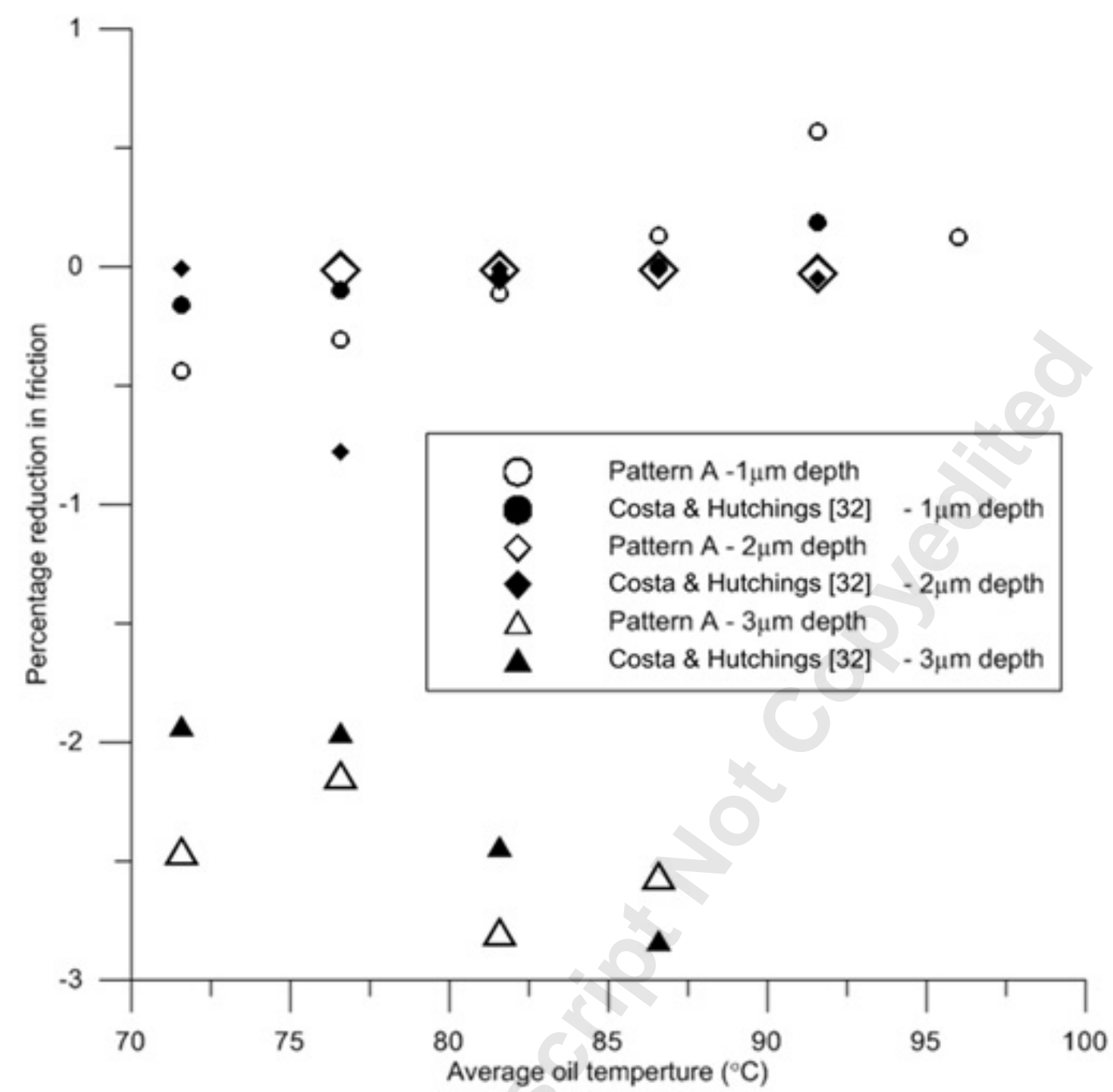

Figure 12: Percentage of reduction in friction using two different texture patterns for the region of -20 to 20 degrees around TDC at different oil temperatures

Figure 13 shows that in the transition from the compression to power stroke through the TDC (crank angles between $-5^{\circ}$ to $5^{\circ}$ ), the main contribution to friction is through boundary interactions (representing nearly 85\%) of the total friction. The remainder is clearly due to viscous friction, indicating that the regime of lubrication is mixed. With texturing, Figure 13 shows that there is a reduction in the proportion of total friction due to boundary interaction. This reduction in friction is quite marginal as also already indicated in Figure 12, nevertheless quite significant given the large number of cycles in any driving condition and the number of vehicles globally. 


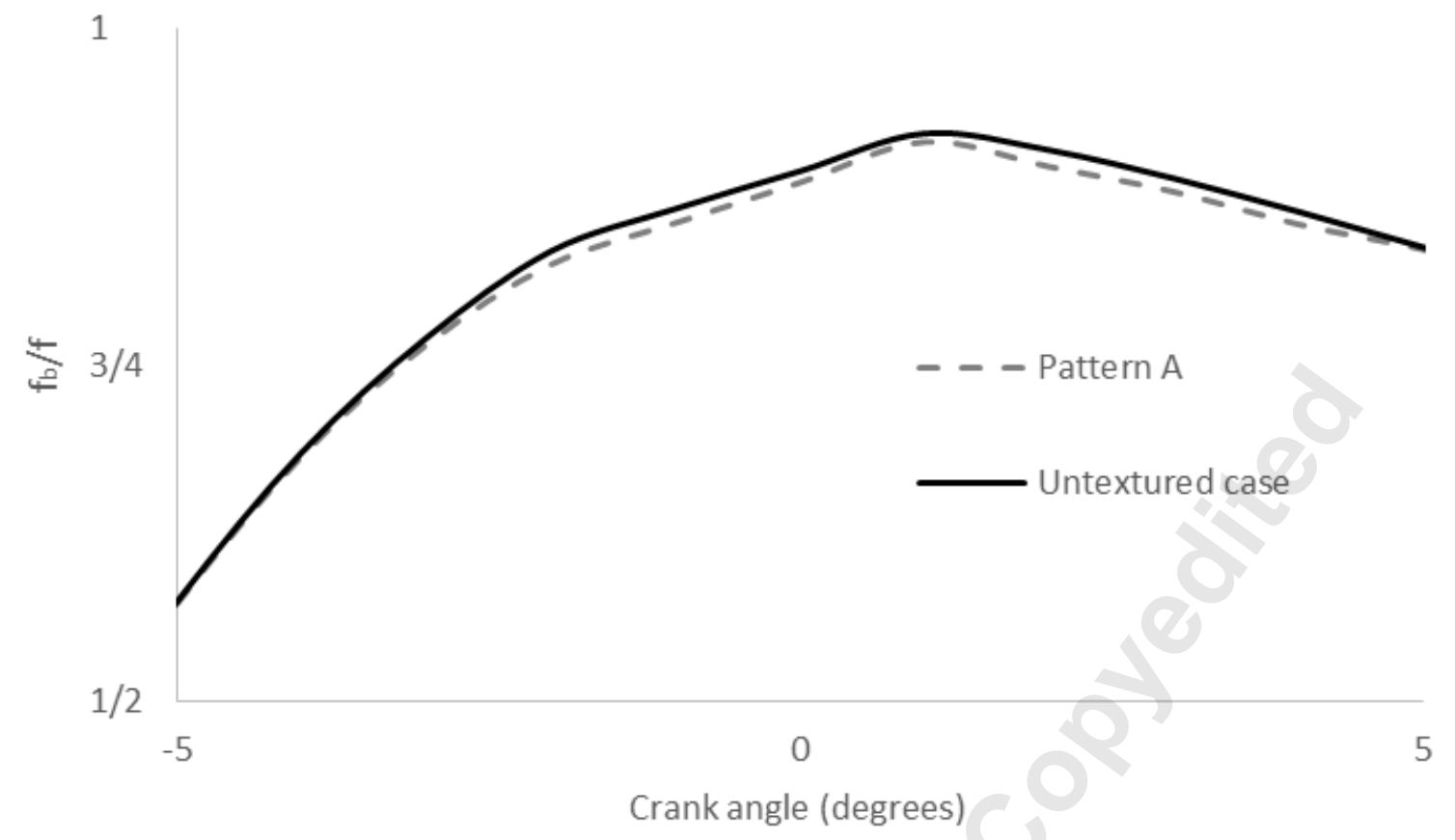

Figure 13: Proportion of boundary friction in the total generated friction at TDC reversal at liner temperature of $92^{\circ} \mathrm{C}$

The underlying mechanism responsible for reduced boundary interactions is pressure perturbations caused by the discontinuities in the contact profile because of the presence of texture features at their leading edge. This is shown by Morris et al [36]. This effect is also shown in Figure 14 with perturbations noted over the chevron features. Interestingly, the mechanism, known as micro-hydrodynamics, is reminiscent of pressure perturbations caused by the rough cartilage in endo-articular joints of all vertebrae species [56]. 


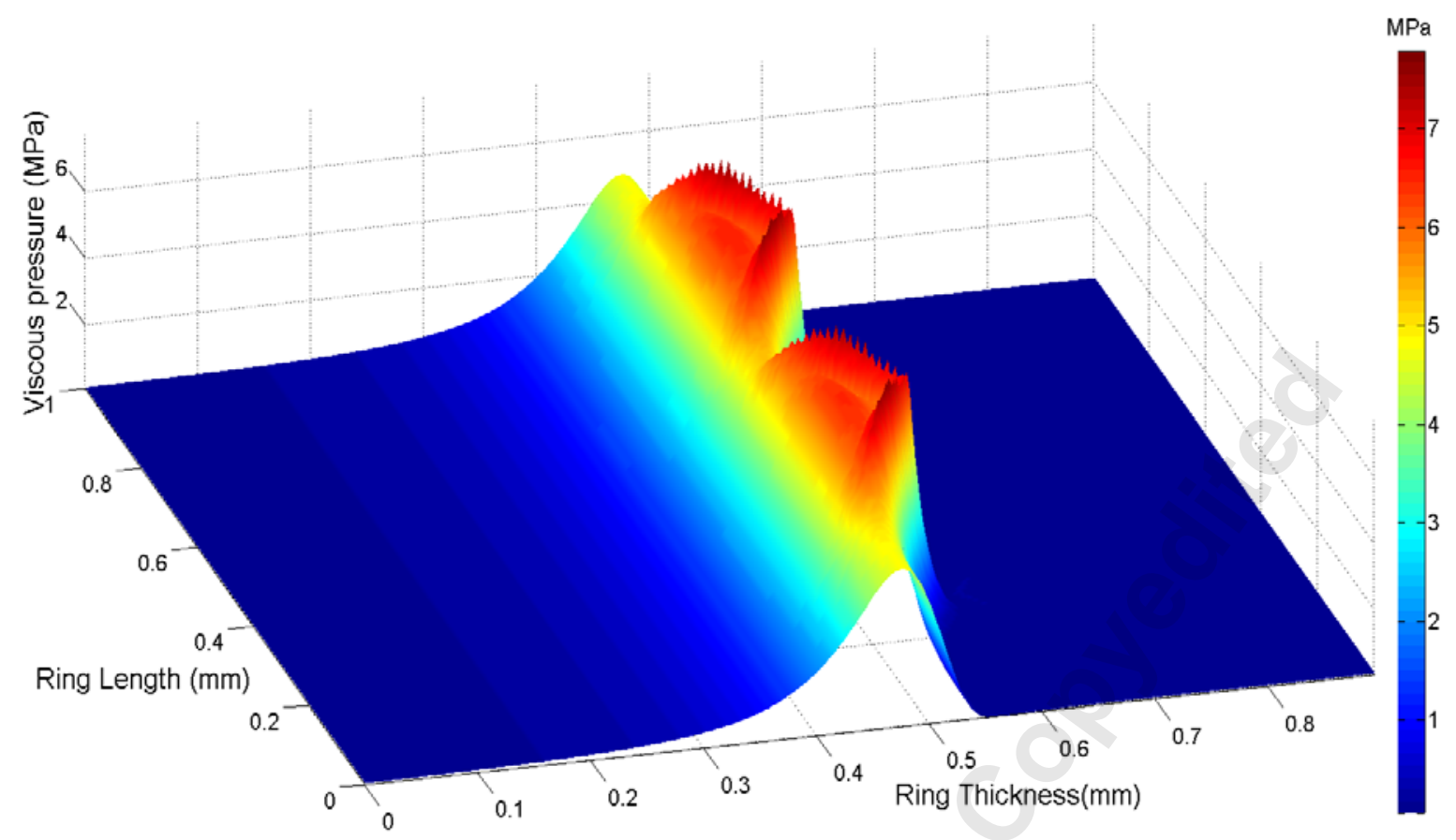

Figure 14: Micro-hydrodynamic pressure perturbations over textured area

\section{Conclusions}

The gain in friction is quite marginal ( 1\%) as shown in Figure 12. Of course this depends on the ring and texture geometry. Some experimental works, based on the power gain have shown gains of $2-4 \%$ at higher engine speeds and lower operating temperatures [24, 25]. One can surmise that shallower features will guard against oil loss that would be a concern with deep reservoirs of lubricant on the surface of the liner at the ring reversal position. The marginal improvement in frictional losses is also affected by temperature because of reducing lubricant viscosity. Therefore, the effectiveness of surface textures in working engine cylinders depends upon a host of parameters, beyond the feature type and geometry alone, including surface topography and operating conditions. Further research should include multi-parameter optimisation, including the effect of lubricant rheology, ring geometry, surface topography as well as texture form, distribution and proper positioning of these with respect to the ring reversal location.

\section{Acknowledgements}

The authors would like to express their gratitude to the Engineering and Physical Sciences Research Council (EPSRC) for the sponsorship of this research under the Encyclopaedic Program Grant (www.Encyclopaedic.org). Thanks are also extended to the other partner organisations.

\section{References}

[1] Andersson, B.S., 1991, “Company’s perspective in vehicle tribology,” In: Dowson, D., Taylor, C.M., and Godet, M., (editors), Proc. $18^{\text {th }}$ Leeds-Lyon Sympos., Elsevier, pp. 503-506. 
[2] Etsion, I., and Sher, E., 2009, "Improving fuel efficiency with laser surface textured piston rings,” Tribology International, 42(4), pp. 542-547.

[3] Howell-Smith, S., Rahnejat, H., King, P.D., and Dowson, D., 2014, "Reducing in-cylinder parasitic losses through surface modification and coating," Proc. IMechE, Part D: J. Automobile Engineering, 228(4), pp. 391-402.

[4] Tian, T., Noordzij, L.B., Wong, V.W., and Heywood, J. B., 1998, "Modelling Piston-Ring Dynamics, Blowby, and Ring-Twist Effects,” Trans. ASME, J. Eng Gas Turbines \& Power, 120, pp. 843-854.

[5] Baker, C.E., Theodossiades, S., Rahnejat, H., and Fitzsimons, B., 2012, "Influence of inplane dynamics of thin compression rings on friction in internal combustion engines,” J. Eng. for Gas Turbines and Power, 134(9), ASME Paper No. 092801 -092801-11.

[6] Chong, W.W.F., Teodorescu, M., and Vaughan, N.D., 2011, "Cavitation induced starvation for piston-ring/liner tribological conjunction,” Tribology International, 44(4), pp. 483-497.

[7] Shahmohamadi, H., Rahmani, R., Rahnejat, H., Garner, C.P., and King, P.D., 2013, "Thermo-mixed hydrodynamics of piston compression ring conjunction," Tribology Letters, 51(3), pp. 323-340.

[8] Namazian, M., and Heywood, J.B., 1982, "Flow in the piston-cylinder-ring crevices of a spark-ignition engine: effect on hydrocarbon emissions, efficiency and power," SAE Trans. 91(1), pp. 261-288.

[9] Baker, C.E., Rahmani, R., Karagiannis, I., Theodossiades, S., Rahnejat, H., and Frendt, A., 2014, "Effect of compression ring elastodynamics behaviour upon blowby and power loss," SAE Technical Pap. 2014-01-1669, DOI: 10.4271/2014-01-1669.

[10] Akalin, O., and Newaz G.M., 2001,"Piston ring-cylinder bore friction modeling in mixed lubrication regime: Part I: analytical results,” Trans ASME, J. Tribology, 123, pp. 211-218.

[11] Akalin, O., and Newaz, G.M., 2001,“Piston Ring-Cylinder Bore Friction Modeling in Mixed Lubrication Regime: Part II - Correlation With Bench Test Data,” Trans. ASME, J. Tribology, 123, pp. 219-223.

[12] Bolander, N.W., Steenwyk, B.D., Sadeghi, F., and Gerber, G.R., 2005, "Lubrication regime transitions at the piston ring-cylinder liner interface,” Proc. IMechE, Part J: J. Eng. Tribology, 219(1), pp. 19-31.

[13] Mishra, P.C., Rahnejat, H., and King, P.D., 2009, “Tribology of the ring-bore conjunction subject to a mixed regime of lubrication,” Proc. IMechE, Part C: J. Mech. Eng. Science, 223, pp. 987-998. 
[14] Rahmani, R., Theodossiades, S., Rahnejat, H., and Fitzsimons, B., 2012, “Transient elastohydrodynamic lubrication of rough new or worn piston compression ring conjunction with an out-of-round cylinder bore,” Proc. IMechE, Part J: J. Eng. Tribology, 226(4), pp. 284-305.

[15] Furuhama, S., and Sasaki, S., 1983, "New device for the measurement of piston frictional forces in small engines,” SAE Pap. No. 831284.

[16] O’Rourke, B., Radford, D., and Stanglmaier, R., 2010, “Tri-axial force measurements on the cylinder of a motorised SI engine operated on lubricants of differing viscosity," Trans. ASME, J. Engng. for Gas Turbines \& Power, 132(9), ASME Paper No. 092807.1-092807.7.

[17] Gore, M., Howell-Smith, S. J., King, P. D., and Rahnejat, H., 2012, "Measurement of InCylinder Friction Using the Floating Liner Principle,” Proc. ASME. 44663, ASME 2012 Internal Combustion Engine Division Spring Technical Conference, DOI: 10.1115/ICES2012-81028.

[18] Gore, M., Theaker, M., Howell-Smith, S., Rahnejat, H., and King, P.D., 2014, "Direct measurement of piston friction of internal-combustion engines using the floating-liner principle,” Proc. IMechE, Part D: J. Automobile Engineering, 228(3), pp. 344-354.

[19] Styles, G., Rahmani, R., Rahnejat, H., and Fitzsimons, B., 2014, "In-cycle and life-time friction transience in piston ring-liner conjunction under mixed regime of lubrication,” Int. J. Engine Research, 15(7), pp. 862-876

[20] Etsion I., 2005, "State of the art in laser surface texturing," Trans. ASME, Series F: J. Tribology, 127(1), pp. 248-253.

[21] Ronen, A., Etsion, I., and Kligerman, Y., 2001, "Friction-reducing surface-texturing in reciprocating automotive components,” Tribology Trans., 44(3), pp. 359-366.

[22] Yu, X.Q, He, S., and Cai, R.L., 2002, "Frictional characteristics of mechanical seals with a laser-textured seal face,” J. Materials processing Technology, 129(1), pp. 463-466.

[23] Pettersson, U., and Jacobson, S., 2007, "Textured surfaces for improved lubrication at high pressure and low sliding speed of roller/piston in hydraulic motors," Tribology Int., 40(2), pp. 355-359.

[24] Rahnejat, H., Balakrishnan, S., King, P. D., and Howell-Smith, S., 2006, "In-cylinder friction reduction using a surface finish optimization technique," Proc. IMechE, Part D: J. Automobile Engineering, 220(9), pp. 1309-1318.

[25] Etsion, I., 2010, "Surface texturing for in-cylinder friction reduction,” In: Rahnejat, H. (Ed.), Triblogy and dynamics of engine and powertrain, New Delhi (India): Woodhead Publishing Ltd. 
[26] Morris, N., Rahmani, R., and Rahnejat, H., 2011, “Tribology of Partial Pad Journal Bearings with Textured Surfaces,” ECOTRIB, 3rd European Conference on Tribology, pp. 645-650

[27] Jiang, Y., Gao, Y., and An, Q., 2014, "Dynamic analysis of the rotor supported by journal bearing with micro-spherical surface texturing,” Proc. IMechE, Part K: J. Multi-body Dynamics, 228(4), pp. 355-365.

[28] Kligerman, Y., Etsion, I., and Shinkarenko, A., 2005, "Improving tribological performance of piston rings by partial surface texturing," Trans. ASME, Journal of Tribology,127(3), pp. 632-638.

[29] Ryk, G., Kligerman, Y. and Etsion, I., 2002, "Experimental Investigation of Laser Surface Textured for Reciprocating Automotive Components”, Tribology Transactions, Vol. 45, No. 4, pp. 444-449

[30] Ryke, G., Kligerman, Y., Etsion, I., Shinkarenko, A., 2005, "Experimental Investigation of Partial Laser Surface Texturing for Piston-Ring Friction Reduction”, Tribology Transactions, Vol. 48, No. 4, pp. 583-588

[31] Ryk, G., Etsion, I., 2006, “Testing piston rings with partial laser surface texturing for friction reduction”, Waer, Vol. 261, pp. 792-796

[32] Checo, H. M., Ausas, R. F., Jai, M., Cadalen, J. P., Choukroun, F., and Buscaglia, G. C., 2014, "Moving textures: Simulation of a ring sliding on a textured liner," Tribology Int., 72, pp. 131-142.

[33] Rahmani, R., Shirvani, A., and Shirvani, H., 2010, "Optimised textured surfaces with application in piston-ring/cylinder liner contact," in: Tribology and Dynamics of Engine and Powertrain: Fundamentals, Applications and Future Trends, Ed. H. Rahnejat, Woodhead Publishing Ltd.

[34] Rahmani, R., Shirvani, A., and Shirvani, H., 2010, “An analytical approach for analysis and optimisation of slider bearings with infinite width parallel textures,” Tribology Int., 43(8), pp. 1551-1565.

[35] Costa, H. L., and Hutchings, I. M., 2007, "Hydrodynamic lubrication of textured steel surfaces under reciprocating sliding conditions,” Tribology Int., 40(8), pp. 1227-1238.

[36] Morris, N., Leighton, M., De la Cruz, M., Rahmani, R., Rahnejat, H. and Howell-Smith, S., 2014, "Combined numerical and experimental investigation of the micro-hydrodynamics of chevron-based textured patterns influencing conjunctional friction of sliding contacts," Proc. IMechE, Part J: J. Eng. Tribology, DOI: 10.1177/1350650114559996.

[37] Rahnejat, H., 1998, Multi-body Dynamics: Vehicles, Machines and Mechanisms, Professional Engineering Publishers (PEP), Bury St Edmunds, UK, ISBN: 0768002699 
[38] Ma, M-T, Sherrington, I., and Smith, E.H., 1997,“Analysis of lubrication and friction for a complete piston-ring pack with an improved oil availability model - Part 1: circumferentially uniform film,” Proc. IMechE, Part J: J. Eng. Tribology, 211, pp. 1-15.

[39] Mishra, P.C., Balakrishnan, S., and Rahnejat, H., 2008, “Tribology of compression ringto- cylinder contact at reversal,” Proc. IMechE, Part J: J. Eng. Tribology, 222, pp. 815-26.

[40] Patir, N., and Cheng, H.S., 1978, “An average flow model for determining effects of three-dimensional roughness on partial hydrodynamic lubrication,” J. Tribology, 100, pp. 1217.

[41] Spencer, A., Dobryden, I., Almqvist, N., Almqvist, A., and Larsson, R. 2013, “The influence of AFM and VSI techniques on the accurate calculation of tribological surface roughness parameters,” Trib. Int., 57, pp. 242-250.

[42] Gohar, R., and Rahnejat, H., 2008, Fundamentals of Tribology, Imperial College Press, London, UK, ISBN-13 978-1-84816860-2

[43] Houpert, L., 1985, "New results of traction force calculations in elastohydrodynamic Contacts,” Trans. ASME, Series F: J. Tribology, 107(2), pp. 241-245.

[44] Dowson, D., and Higginson, G.R., 1959, "A numerical solution to the elastohydrodynamic problem,” J. Mech. Eng. Sci., 10(1), pp. 6-15.

[45] Larsson, R., Larsson, P.O., Eriksson, E., Sjöberg, M., and Höglund, E., 2000, “Lubricant properties for input to hydrodynamic and elastohydrodynamic lubrication analyses," Proc. IMechE, Part J: J. Eng. Tribology, 214(1), pp. 17-27.

[46] Arcoumanis, C., Duszynski, M., Flora, H. and Ostovar, P., 1995, “Development of a piston-ring lubrication test-rig and investigation of boundary conditions for modelling lubricant film properties”, SAE Technical Pap. No. 952468

[47] Elrod, H.G., 1981, “A cavitation algorithm,” Trans. ASME, J. Lubrication Technology, 103(3), pp. 350-354.

[48] Gulwadi, S.D., 2000, "Analysis of tribological performance of a piston ring pack," Tribology Trans., 43(2), pp.151-162.

[49] Ruddy, B.L., Dowson, D., and Economou, P.N., 1981, “A theoretical analysis of the twin-land type of oil-control piston ring,” Proc. IMechE, Pat C: J. Mech. Eng. Sci., 23(2), pp. 51-62.

[50] Heywood, J.B., 1988, Internal combustion engine fundamentals, New York: McGrawHill, ISBN 0-07-028637-X

[51] Bin Chik, A., and Fessler. H., 1966, "Radial pressure exerted by piston rings,” The Journal of Strain Analysis for Engineering Design, 1(2), pp.165-171. 
[52] Greenwood, J. A., and Tripp, J. H., 1970-71, “The contact of two nominally flat rough surfaces,” Proc. IMechE, J. Mech. Eng. Sci. 185 (1), pp. 625-633.

[53] Teodorescu, M., Balakrishnan, S., and Rahnejat, H., 2005, "Integrated tribological analysis within a multi- physics approach to system dynamics,” Trib. \& Interface Sci. Series, Elsevier, 48, pp.725-737.

[54] Briscoe, B. J., and Evans. D. C. B., 1982, "The shear properties of Langmuir-Blodgett layers,” Proc. Roy. Soc., Series A, Math. and Phy. Sci, pp.389-407.

[55] Gore, M., Theaker, M., Howell-Smith, S., Rahnejat, H., and King, P.D., 2014, "Direct measurement of piston friction of internal-combustion engines using the floating-liner principle,” Proceedings of the Institution of Mechanical Engineers, Part D: J. Auto. Eng., 228 (3), pp. 344-354

[56] Dowson, D. and Jin, Z.M., 1986, "Micro-elastohydrodynamic lubrication of synovial joints", Engineering in Medicine, 15(2), pp. 63-65. 